\title{
Analysis of De-Laval nozzle designs employed for plasma figuring of surfaces
}

\author{
Nan $\mathrm{Yu}^{1} \cdot$ Renaud Jourdain $^{1} \cdot$ Mustapha Gourma $^{2} \cdot$ Paul Shore $^{1}$
}

Received: 28 September 2015 / Accepted: 9 February 2016 / Published online: 27 February 2016

(C) The Author(s) 2016. This article is published with open access at Springerlink.com

\begin{abstract}
Plasma figuring is a dwell time fabrication process that uses a locally delivered chemical reaction through means of an inductively coupled plasma (ICP) torch to correct surface figure errors. This paper presents two investigations for a high temperature jet $(5000 \mathrm{~K})$ that is used in the context of the plasma figuring process. Firstly, an investigation focuses on the aerodynamic properties of this jet that streamed through the plasma torch De-Laval nozzle and impinged optical surfaces. Secondly, the work highlights quantitatively the effects of changing the distance between the processed surface and nozzle outlet. In both investigations, results of numerical models and experiments were correlated. The authors' modelling approach is based on computational fluid dynamics (CFD). The model is specifically created for this harsh environment. Designated areas of interests in the model domain are the nozzle convergent-divergent and the impinged substrate regions. Strong correlations are highlighted between the gas flow velocity near the surface and material removal footprint profiles. In conclusion, the CFD model supports the optimization of an ICP torch design to fulfil the demand for the correction of ultra-precision surfaces.
\end{abstract}

Keywords Plasma figuring - Inductively coupled plasma . Computational fluid dynamics $\cdot$ Material removal footprint

$\mathrm{Nan} \mathrm{Yu}$

n.yu@ cranfield.ac.uk

1 Precision Engineering Institute, School of Aeronautic, Transport and Manufacturing, Cranfield University, Bedford MK43 0AL, UK

2 Oil and Gas Engineering Centre, School of Energy, Environment and Agrifood, Cranfield University, Bedford MK43 0AL, UK

\section{Introduction}

In the past two decades, thermal plasma technologies have been widely used for a variety of scientific and industrial applications. The applications span from chemical synthesis of new materials, through material spraying or coating, nanopowder preparation, and up to the production of many high quality surfaces [1-4]. Among the large number of plasma delivery systems, inductively coupled plasma (ICP) torches are well suited for processing large components at atmospheric pressure. ICP design is itself well-understood and contamination free since no electrodes are required. Reed [5] reported the first ICP torch operated at atmospheric pressure in 1961. In the late 1990s, Carr [6, 7] pioneered the plasma figuring by correcting the figure of large optical components. More recently in 2007, Fridman et al. [8] extended public knowledge through the study of transport phenomena in plasma torches.

ICP torches have been modified to create highly collimated and stable plasma beams. With regards to the plasma figuring application, typically fluorine compounds $\left(\mathrm{SF}_{6}\right)$ are introduced in the core of the plasma and are given the time to go through the length of the plasma. This exposure leads to the creation of fluorine ions (reactive species). Upon impingement, these fully ionized fluorine ions react with silicon-based substrates to form gases $\left(\mathrm{SiF}_{4}\right.$ and $\left.\mathrm{SO}_{2}\right)$ resulting in material removal etching. In the context of this work, dedicated nozzles enable to enhance the performance of the plasma jet. These nozzles are called DeLaval and they are characterized by a convergent-divergent regions, inlet-outlet. Nozzles are positioned at the end of the ICP torch quartz tube (Fig. 1, right) [9, 10]. If axisymmetric, nozzles are able to amend the beam diameter, the beam cross-section heat transfer intensity, and the plasma velocity without any requirements for engineering modifications on the torch body.

Numerical simulations of the plasma jet are considered essential to investigate and understand the dynamic of the high 
Fig. 1 Standard ICP torch (left) and ICP torch equipped with a De-Laval nozzle (right)

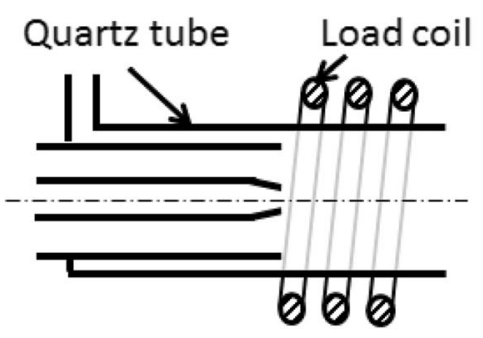

temperature gas (HTG) flow and occurred chemical reactions. Previous work has focused on the magnetohydrodynamics of the plasma within the plasma core. Boulos and Mostaghimi $[11,12]$ built $1 \mathrm{D}$ models with laminar flow to solve the electromagnetic field equations. Nishiyama $[3,13]$ reported that the secondary gas (cold helium) could control the temperature and flow field in radio frequency (RF) ICP. Colombo and Bernardi [14-16] have created both 2D and 3D models for investigating the effects of the torch geometries on the plasma flow and temperature distributions.

In those aforementioned investigations, the operating power varied from 3 up to $10 \mathrm{~kW}$, while the frequencies in all cases were set to $3 \mathrm{MHz}$. Experimental validation is challenging. Boulos and Nishiyama have successfully compared their modelling results with experimental data, in regards to radial velocity distribution [12] and axial temperature distribution [13]. Morsli and Proulx validated their models by comparing calculated axial temperature profiles and discrete temperature measurements [17, 18]. Authors have based their own work on the modelling approach of the aforementioned publications but have focused on HTG that flows through the nozzle and in experimental conditions that were totally different (see Section 2).

\section{CFD simulation principle and method}

CFD simulation was carried out using the commercial software FLUENT [19]. This CFD model was utilized for the investigation of the aerodynamic behaviour of the RF plasma jet. Thus two domains, A and B, are described hereafter. In Fig. 2, domain $\mathrm{A}$ is dominated by intense electromagnetic (EM) field and temperatures. Domain $\mathrm{A}$ is where the dissociation and ionization take place. Domain B is where both the transportation and etching take place. The authors' interest is focused on the plasma jet - called HTG throughout this paper-flow dynamic and the transport of radical species, in domain $\mathrm{B}$.

\subsection{Modelling hypothesis}

The main modelling assumptions adopted are:

(1.) The HTG flow is axisymmetric, steady, and turbulent.

(2.) The effect of EM fields is negligible.
(3.) Viscous dissipation is taken into account.

(4.) The Local Thermal Equilibrium (LTE) is achieved.

(5.) The HTG is thermally expansible and mechanically incompressible.

\subsection{Governing equations}

We have considered a steady state regime with 2D axisymmetric model based on a HTG that is governed by the NavierStokes momentum equation, conservation of mass and energy transport. The nomenclatures are provided with those governing equations.

\subsubsection{Continuity equation}

$\frac{\partial\left(\rho v_{z}\right)}{\partial z}+\frac{1}{r} \frac{\partial\left(\rho r v_{r}\right)}{\partial r}=0$

where $\rho$ is the gas density, while $v_{\mathrm{z}}$ and $v_{\mathrm{r}}$ stand for the gas velocity in axial and radial directions, respectively.

\subsubsection{Momentum equation}

$$
\begin{aligned}
\rho\left[\frac{\partial v_{z}}{\partial z} v_{z}+\frac{\partial v_{z}}{\partial r} v_{r}\right]= & -\frac{\partial p}{\partial z}+\frac{\partial}{\partial z}\left[\mu\left(2 \frac{\partial v_{z}}{\partial z}\right)\right] \\
& +\frac{1}{r} \frac{\partial}{\partial r}\left[\mu r\left(\frac{\partial v_{r}}{\partial z}+\frac{\partial v_{z}}{\partial r}\right)\right] \\
\rho\left[\frac{\partial v_{r}}{\partial r} v_{r}+\frac{\partial v_{r}}{\partial z} v_{z}\right]= & -\frac{\partial p}{\partial r}+\frac{\partial}{\partial r}\left[\mu\left(2 \frac{\partial v_{r}}{\partial r}\right)\right] \\
& +\frac{\partial}{\partial z}\left[\mu\left(\frac{\partial v_{r}}{\partial z}+\frac{\partial v_{z}}{\partial r}\right)\right] \\
& +\frac{2 \mu}{r}\left(\frac{\partial v_{r}}{\partial r}-\frac{v_{r}}{r}\right)
\end{aligned}
$$

Where $p$ is the pressure in the nozzle and $\mu$ is the viscosity. 
Fig. 2 Cross-section of the ICP torch (domain A) and the dedicated De-Laval nozzle (domain B). $Q 1$ : reactive gas (0.8 slm SF6), Q2: auxiliary gas (0.2 slm argon), and $Q 3$ : shielding gas (20 slm argon)

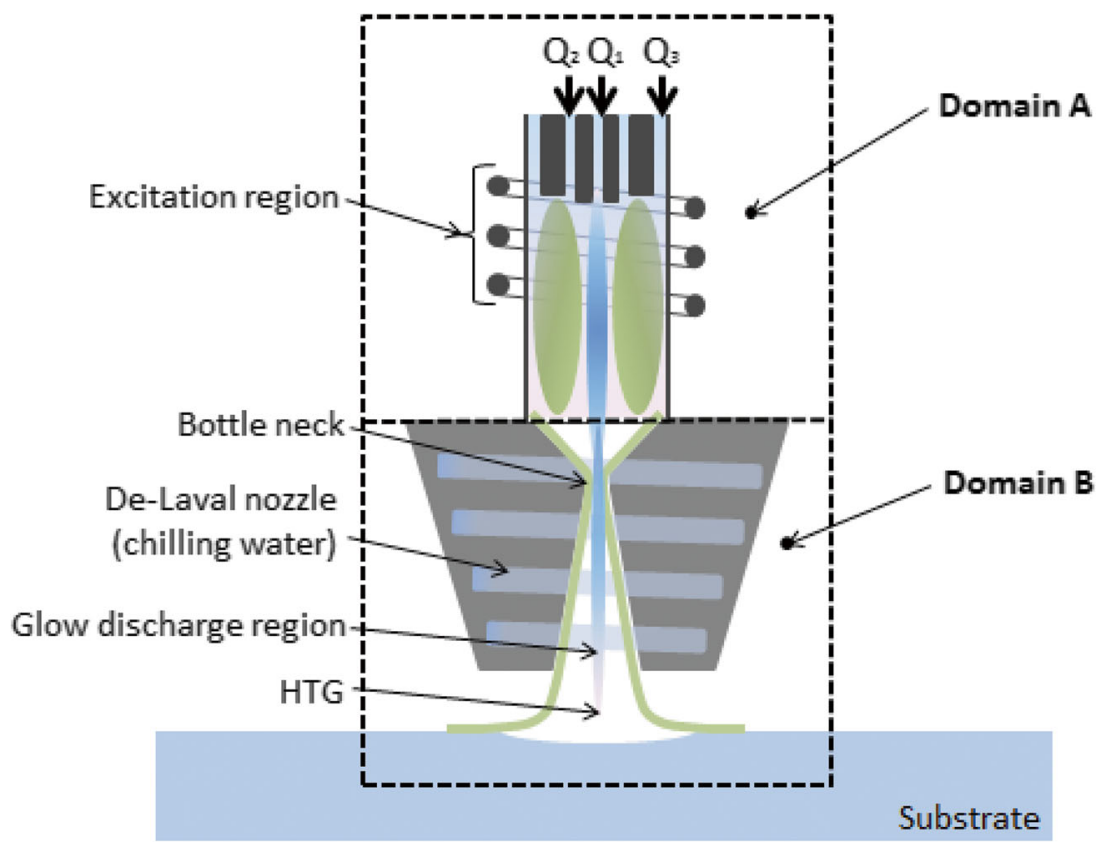

\subsubsection{Energy equation}

$$
\begin{aligned}
\rho\left[\frac{\partial h}{\partial r} v_{r}+\frac{\partial h}{\partial z} v_{z}\right]= & \frac{\partial}{\partial z}\left(\frac{\lambda}{c_{p}} \frac{\partial h}{\partial z}\right)+\frac{1}{r} \frac{\partial}{\partial r}\left(r \frac{\lambda}{c_{p}} \frac{\partial h}{\partial r}\right) \\
& +U_{P}-U_{R}+U_{C}
\end{aligned}
$$

Where $c_{p}$ is the specific heat at a constant pressure, $\lambda$ is the thermal conductivity and $h$ is static enthalpy.

For ideal incompressible gas, the static enthalpy $h=\Sigma_{\mathrm{j}}$ $Y_{\mathrm{j}} h_{\mathrm{j}}$, where $Y_{\mathrm{j}}$ is the local mass fraction of species $\mathrm{j}$ and $h_{\mathrm{j}}$ is the enthalpy of species $\mathrm{j} ; U_{p}, U_{R}, U_{C}$ are local plasma energy dissipation rate, Joule heating rate, volumetric radiation heat losses-Radiation losses per unit volume, and heat of chemical reaction, respectively. In the case of the present work, using the hypothesis mentioned above, $U_{p}$ and $U_{C}$ is counted as 0 .

\subsubsection{Turbulence characteristics}

The characteristic of plasma flow is estimated on the basis of the Reynolds number and additional information from literature. $R e=\frac{\rho v D_{\mathrm{H}}}{\mu}$, where $\rho$ is the density of he fluid [20], $v$ is the mean velocity of the fluid, $D_{\mathrm{H}}$ is the hydraulic diameter of the nozzle, $\mu$ is the dynamic viscosity of the fluid [21]. These parameters were considered at the inlet of the nozzle. Due to a wide range of parameter values the $R e$ numbers range from 3800 to 10,350 . This $R e$ result suggests that the flow is in transition state with both turbulent and laminar transports [22]. On the other hand, Morsli [23] reported that the turbulence is present in the cooler regions (below $5000 \mathrm{~K}$ ) of ICP torch jets. Also it is detailed that the laminar flow is promoted due to the lower densities and higher viscosities at the centre of the plasma stream (above $5000 \mathrm{~K}$ ).

In the case of the present work, the temperature of the HTG is below $5000 \mathrm{~K}$ [24]. Then, the HTG jets' turbulent behaviour is described using the standard $k-\varepsilon$ scheme [25]. This turbulence model is used because it is an accepted practice and it offers balance between accuracy and speed of convergence. Also for computing Reynolds stresses two additional transport equations were solved. Kinetic turbulent energy $k$ and its dissipation rate $\varepsilon$ equations are shown in (5) and (6).

$$
\frac{\partial\left(\rho k u_{i}\right)}{\partial x_{i}}=\frac{\partial}{\partial x_{j}}\left[\left(\mu+\frac{\mu_{t}}{\sigma_{k}}\right) \frac{\partial k}{\partial x_{j}}\right]+G_{k}-\rho \varepsilon
$$

$\frac{\partial\left(\rho \varepsilon u_{i}\right)}{\partial x_{i}}=\frac{\partial}{\partial x_{j}}\left[\left(\mu+\frac{\mu_{t}}{\sigma_{\varepsilon}}\right) \frac{\partial \varepsilon}{\partial x_{j}}\right]+C_{1 \varepsilon} \frac{\varepsilon}{k} G_{k}-C_{2 \varepsilon} \rho \frac{\varepsilon^{2}}{k}$

The quantities of $C_{1 \varepsilon}, C_{2 \varepsilon} \sigma_{k}$, and $\sigma_{\varepsilon}$ are empirical constants [19]. The turbulent viscosity $\mu_{\mathrm{t}}$ involves a constant $\mathrm{c}_{\mu}=0.09$ and is derived from $k$ and $\varepsilon$, as shown in (7):

$\mu_{t}=c_{\mu} \cdot \rho \cdot \frac{k^{2}}{\varepsilon}$

The source term of turbulence $G_{k}$ is function of turbulent viscosity and stresses, as shown in (8):

$$
G_{k}=\mu_{t}\left(\frac{\partial u_{i}}{\partial x_{j}}+\frac{\partial u_{j}}{\partial x_{i}}\right) \frac{\partial u_{j}}{\partial u_{i}}-\frac{2}{3} k \frac{\partial u_{i}}{\partial x_{i}}
$$


Fig. 3 Computational domain in [17]

Fig. 4 Correlation between benchmark model [17] and author's validation models. a axial pressure profiles. $\mathbf{b}$ axial temperature profiles
Axial length
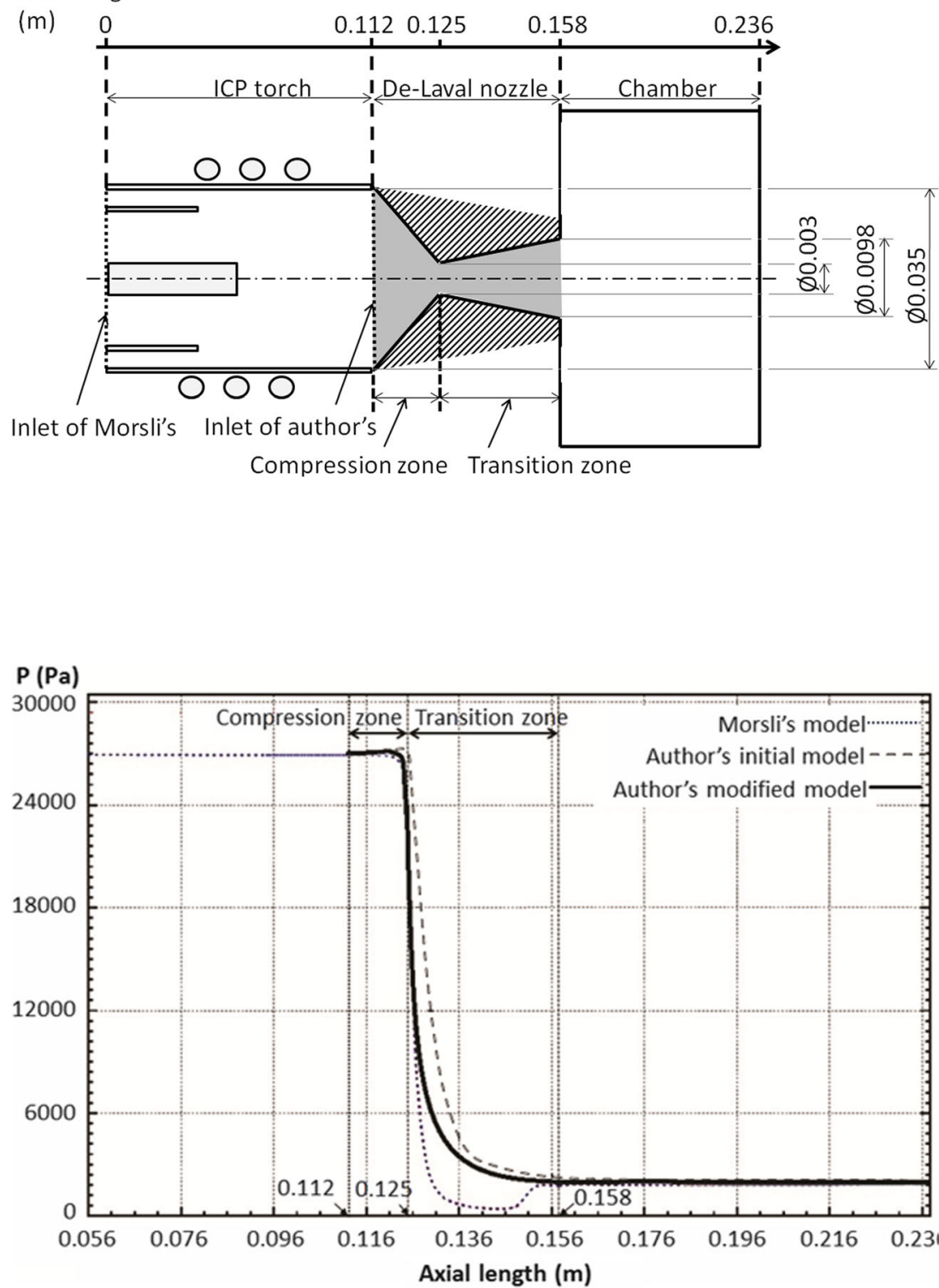

$\mathbf{T}(\mathrm{K})$

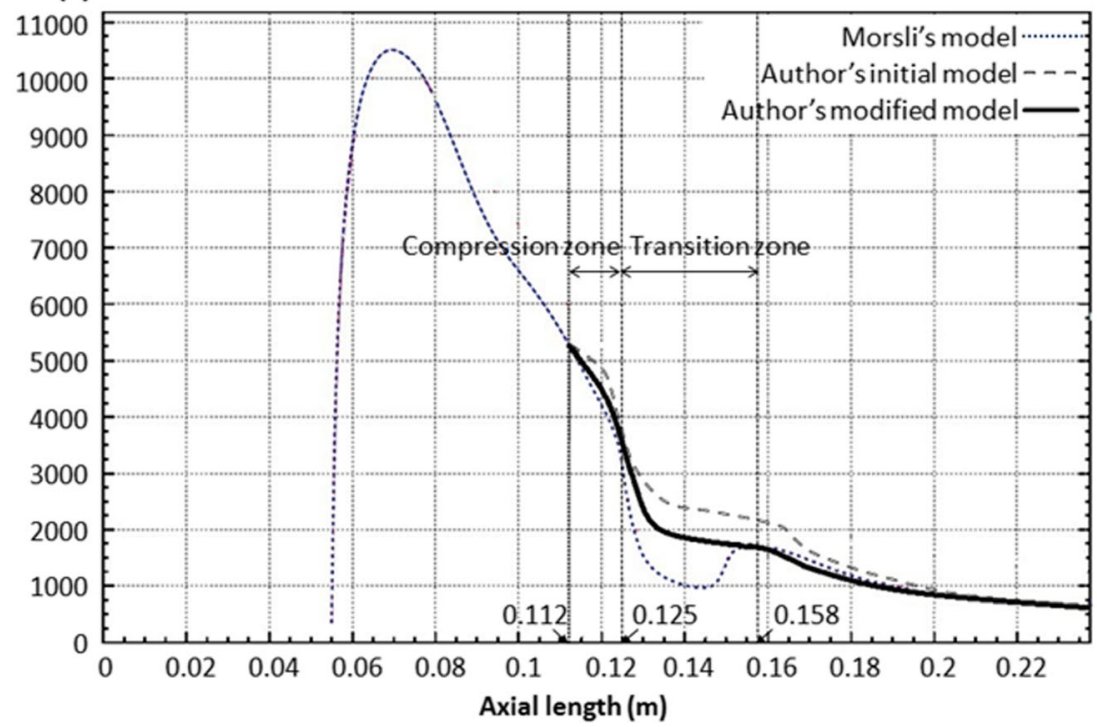




\subsection{Initial validation of author's modelling approach}

The authors took the plasma model published by Morsli and Proulx [17] as a benchmark. The geometries of torch, nozzle, and chamber of this model are shown in Fig. 3. The other boundary conditions (BC) were applied identically. However the approach adopted here by the authors considered a HTG that flows through the De-Laval nozzle and into the chamber. Unlike in Morsli's model, the calculation begun at the inlet of the nozzle.

$\mathrm{BC}$ related with the geometry of this model include nozzle inlet diameter $0.035 \mathrm{~m}$, nozzle throat diameter $0.003 \mathrm{~m}$, and length of convergent path $0.012 \mathrm{~m}$. BCs related to temperatures are nozzle wall $700 \mathrm{~K}$ and chamber wall $300 \mathrm{~K}$. In addition, authors used the three main results of Morsli's work. Results are the axial distributions of inlet pressure, inlet temperature and gas flow rate. These input axial parameters located at the entrance of the nozzle are inlet pressure 27,000 Pa, inlet temperature $6000 \mathrm{~K}$, and gas flow rate $3.58 \times 10^{-3} \mathrm{~kg} \mathrm{~s}^{-1}$.

In their research, Morsli highlighted that the distributions of pressure and temperature exhibit important variations along the central line of the torch. Depending on the position along the central line, these variations are either smooth or abrupt. Then, the authors decided to name these two identified zones of interest. These zones are called "Compression zone" and "Transition zone", and they are illustrated in Fig. 3 and mentioned again in Fig. 4.

Two models were implemented by the authors. The author's model results are displayed in Fig. 4 along with Morsli's results. The characteristic and the relative error values are provided hereafter.

The author's initial model was characterized by a uniform inlet profiles of temperature and velocity. The error obtained in the axial pressure and temperature was $\delta=15 \%$. The author's modified model using parabolic profiles for temperature and velocity allows obtaining better results. Compared to the author's initial model, the error was improved. In fact, the relative error obtained was $\delta=5 \%$.

The approach adopted to calculate the relative error $\delta$ is as follow; let $\psi_{\text {ben }}$ (i) and $\psi_{\text {act }}$ (i) be the benchmark model and the actual pressure or temperature calculated at positions $i$, then

$\delta=\frac{\sum_{i}\left|\psi_{\text {ben }}(i)-\psi_{\text {act }}(i)\right|}{\sum_{i} \psi_{\text {ben }}(i)}$

Regarding these two zones of interest, a detailed comparison is presented hereafter. Compression zone is where flow acceleration occurs. In this zone-axial length 0.112 to $0.125 \mathrm{~m}$ in Fig. 4 - pressures slightly built up and temperatures drop further. The author's modified model shows a clear correlation with Morsli's results. On the other hand, the transition zone results - axial length $0.125 \mathrm{~m}$ to $0.158 \mathrm{~m}$ in Fig. 4-highlight some discrepancy with Morsli's model. The authors attribute this discrepancy to the dependency of the pressure and the chemical composition of plasma in Morsli's model. Unlike in Morsli's model, the author's equation of state is not dependent of the constituents. Indeed, this model contained only one constituent.

The pressure and temperature profiles are in good agreement with Morsli's model. Based on the aforementioned comparison, the author's model was considered sufficiently valid to investigate the study case presented in the next section.

\subsection{Experimental BC and numerical procedure}

In our computational domain - domain $\mathrm{B}$, which is shown in Fig. 5, the HTG was a mixture of argon and $0.4 \% \mathrm{SF}_{6}$. This
Fig. 5 Computational domaindomain B - of the model and its geometry (unit $\mathrm{mm}$ )

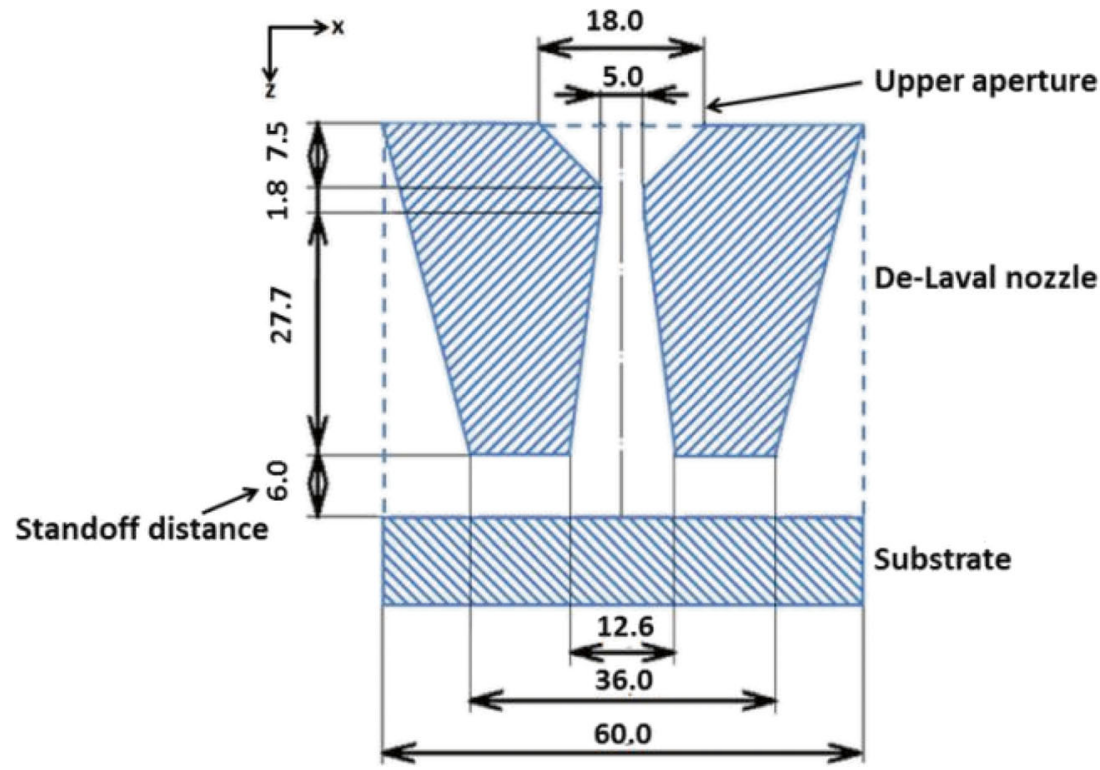



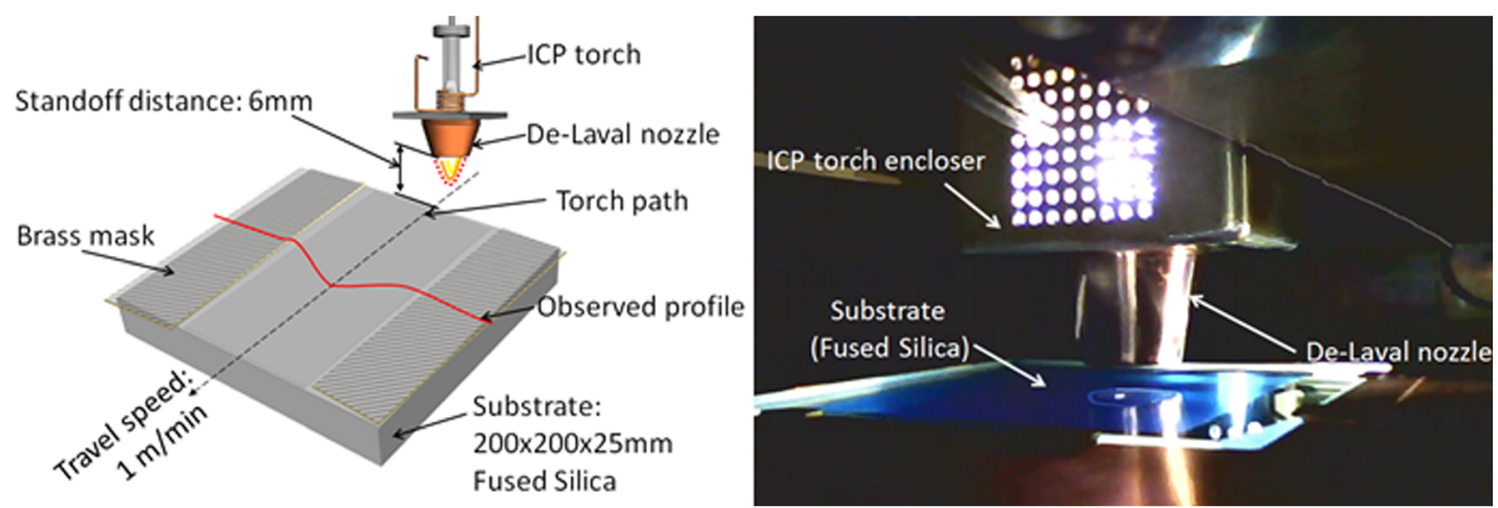

Fig. 6 Schematic of the torch path (left), picture of both substrate and torch (right)

gas mixture (Ar, $\mathrm{Ar}^{+}, \mathrm{SF}_{6}, \mathrm{~F}^{-}, \mathrm{e}^{-}$) is fed into the nozzle through the upper aperture and it flows downward in an axisymmetric manner. From this aperture, the input parameters include the following: flow velocity profile, temperature profile, and pressure. The input temperature of the upper aperture ranges from 1000 to $6500 \mathrm{~K}$ as supported by the measurement of O'Brien [24]. The flow rate of the gas mixture of the torch used for the author work is $221 \mathrm{~min}^{-1}$. The gas mixture velocity in the nozzle inlet is $25.77 \mathrm{~m} \mathrm{~s}^{-1}$. This value was estimated from Rankin-Hugoniot relation. For the sake of simplicity, the temperature of the Fused Silica substrate is set to $400 \mathrm{~K}$ uniformly. And wall temperature of the nozzle is $350 \mathrm{~K}$. The static pressure in the processing chamber is set $101,325 \mathrm{~Pa}$ (outlet side). Also, the gas temperature of the chamber is $300 \mathrm{~K}$.

A coupled implicit solver for the Navier-Stokes equations was used to deal with the strong coupling of momentum and energy equations. The convergence criterion was set to $10^{-5}$. Also, the mesh independence was performed to detect any discretization errors. The dimensions of the De-Laval nozzle and the standoff distance between the nozzle and the substrate are displayed in Fig. 5.

\section{Material removal experiment}

In order to assess correlation of the model output with the actual plasma removal process, a set of footprint material removal experiments were carried out. Footprints were characterized by two parameters. The first parameter is 6 sigma $(\mathrm{mm})$ value which related to the width of material removal footprint (as shown in Fig. 7). The second parameter is the depth $(\mathrm{nm})$ of footprint. The experimental results are compared to the numerical results in Section 4.3.

\subsection{Experimental setup}

The ICP torch was moved in a plane parallel to the surface $200 \mathrm{~mm} \times 200 \mathrm{~mm}$ of a substrate. The substrate was made of fused silica. Brass masks were used (Fig. 6, left) for reference purposes to ensure these two regions were etched free. Picture of both substrate and ICP torch is shown in Fig. 6 (right).

Key experimental conditions include the following: RF signal frequency $40 \mathrm{MHz}$, plasma forwarded power $1.2 \mathrm{KW}$, travel speed of the torch $1 \mathrm{~m} / \mathrm{min}$, and reactive gas $\mathrm{SF}_{6}$ concentration $0.4 \%$ in argon. A series of single trenches were etched on substrate surfaces. The surface topography-100$\mathrm{mm}$ diameter area-was measured using a Twyman-Green interferometer-FISBA Optik $\mu$-Phase [26]. Subsequently, a series of trenches were carried out with different standoff distances. The experimental results are detailed hereafter.

\subsection{Footprint results}

For standoff distance equal to $6 \mathrm{~mm}$, the profile of the etched footprint (Fig. 7) was assessed to be near Gaussian, and the 6 sigma value was determined to be $31 \mathrm{~mm}$. The maximum depth of the trench was $120 \mathrm{~nm}$. When the standoff distances were changed, different footprint depths were observed. The influence of the standoff distance on the maximum depth can be seen in Fig. 8. The beam footprint characterization was

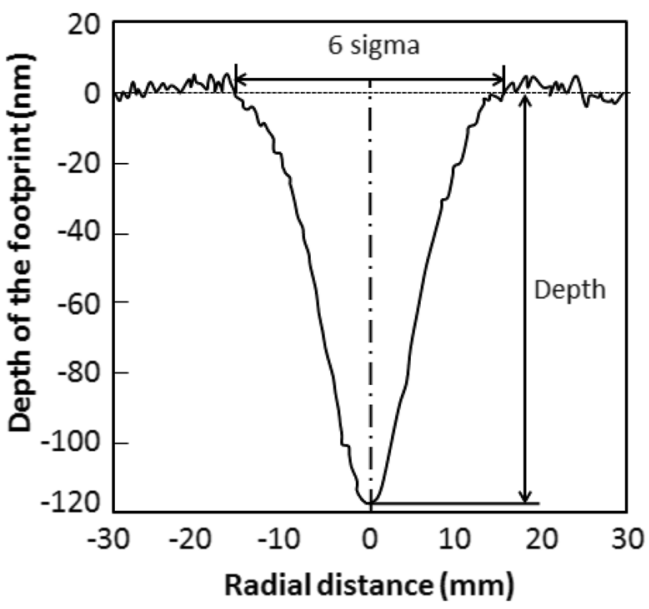

Fig. 7 Cross section of the trench 


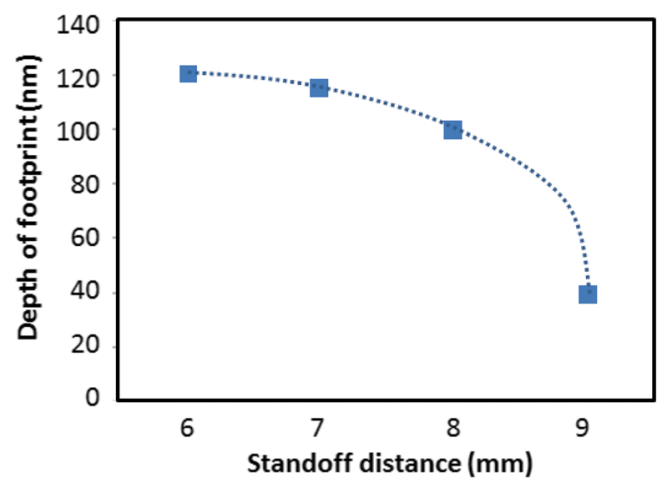

Fig. 8 Depth of trench footprint versus standoff distance

published in [10]. In this work, the footprint data will be utilized to validate the CFD simulation results.

\section{Results}

\subsection{Calculated results of the HTG in De-Laval nozzle}

The calculated distributions for Mach number and temperature in the domain are illustrated in Fig. 9. The Mach number reaches the value of 0.56 in the bottle neck of the nozzle. This velocity is still subsonic as expected.

From the results plotted above, it is clear that the symmetric axis of the nozzle is a critical path that is further scrutinized. The variation of temperatures and velocities along the axis are displayed in Fig. 10 (left). The static pressure is displayed in Fig. 10 (right). The pressure in the nozzle drops significantly by an axial distance of $5 \mathrm{~mm}$. This low pressure is formed in the bottle neck, where the flow velocity reaches $440 \mathrm{~m} / \mathrm{s}$. And, as expected, the pressure value recovers in the divergent area of the nozzle.
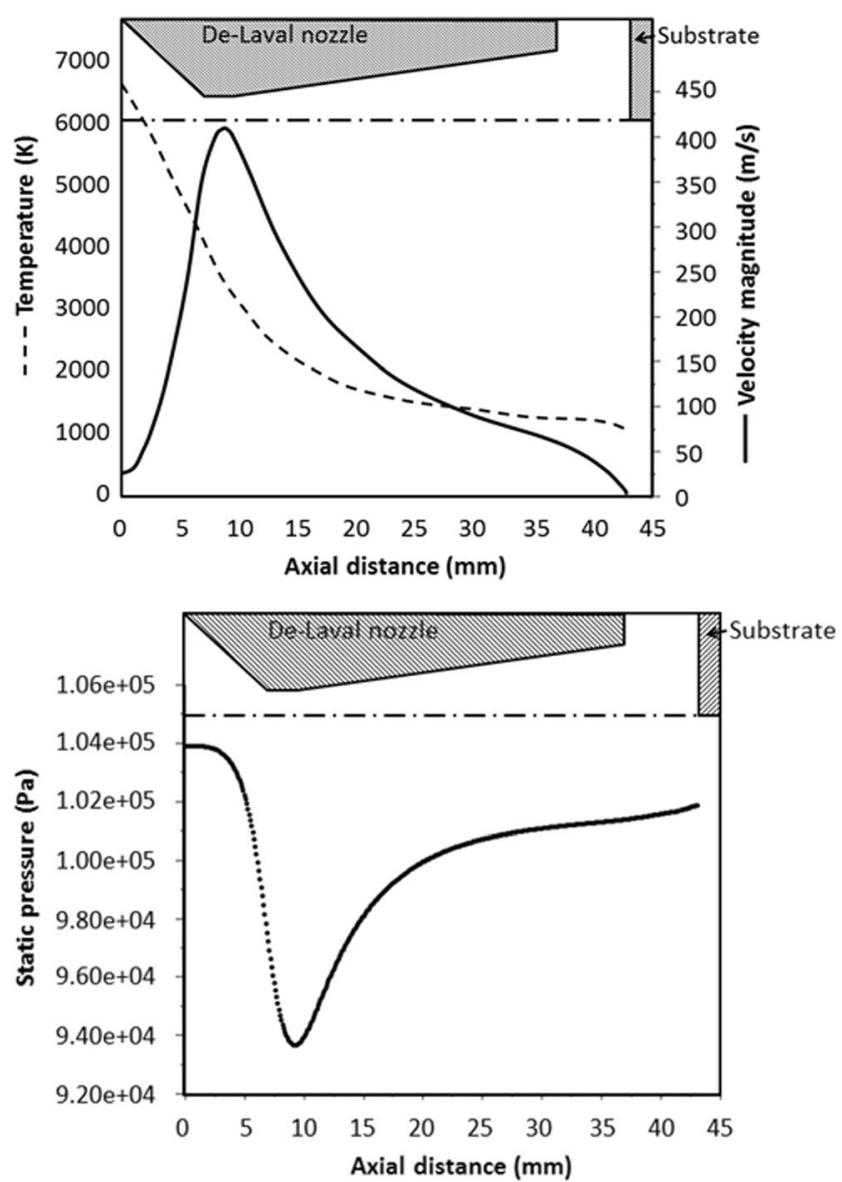

Fig. 10 Axial profiles of temperature, blue dotted line and velocity, black solid line (left), Static pressure along the symmetric axis of the De-Laval nozzle (right)

The other area of interest is the near surface substrate region where the chemical reaction takes place. In order to ease the investigation, a line of study is defined at $10 \mu \mathrm{m}$ from the substrate surface (Fig. 9, horizontal dash line located above the substrate area). This line is called "Pathway of Investigation" (POI). Along the POI, the chemical reaction related data-temperature, density, axial and radial

Fig. 9 Calculated distribution of the Mach number (left), temperature of HTG (right) ( $x$-axis is radial distance from the symmetric line, and $z$-axis is axial distance along the symmetric line)

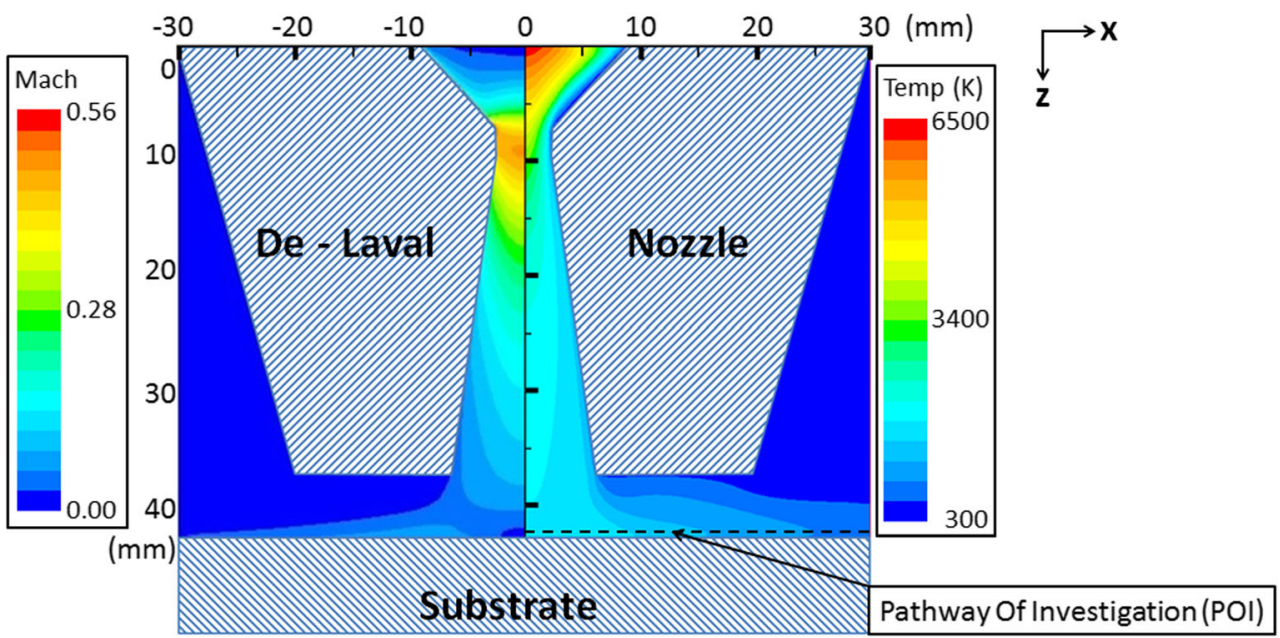


velocity - are extracted and displayed in Fig. 11. In the region close to the symmetric axis, both variables are higher than that of the ambience. Then it can be deduced that the chemical reaction in the centrally exposed region takes place more effectively. Also, in the region far from the symmetric axisradial distance $15 \mathrm{~mm}$ to $30 \mathrm{~mm}$ - fewer silicon atoms are etched. This statement is supported by the evidence-footprint profile—-shown in Fig. 7.

\subsection{Exposed area definition}

From a processing viewpoint, the plasma etching rate is influenced by parameters such as standoff distance of the torch nozzle, the travel speed of the torch, exposure time, the power delivered by the RF generator, and reactive gas concentration. When those aforementioned parameters are coupled together, then a specific near Gaussian shape footprint is created (Fig. 7). However, from a microscopic viewpoint, the plasma etching is considered to take place only in the region exposed to fluorine ions.

In Fig. 12 (left, black solid line), HTG axial velocity along the POI is displayed. As shown, the HTG flow can go either downwards or upwards. The area that experiences downwards HTG flow is shown with positive values of velocity. On the other hand, regions along the POI that experiences an upward HTG flow component are shown having negative values of velocity. The area experiencing downward flow is named "Exposed area". In the next section, the exposed area is characterized by its diameter value. That enables to compare the two profiles of interest: axial velocity and removal footprint.

\subsection{Validation of the CFD simulation with experimental results}

Figure 13 shows both CFD simulation data (Section 4.1) and experimental data-footprint cross section (Section 3.2). This plot highlights the comparison between the material removal footprint and the regions along the POI that experiences a downward vertical flow. The exposed area diameter is $26.8 \mathrm{~mm}$, which is close to the 6 Sigma value of the footprint's aperture $31.1 \mathrm{~mm}$. On the other hand, the two profiles are very similar.

In addition to previous results, the correlation between exposed area diameter and 6 Sigma values is displayed in Fig. 14 for standoff distances set to $6,7,8$, and $9 \mathrm{~mm}$. Good correlation takes place when the standoff distance is smaller than $7 \mathrm{~mm}$, and the discrepancy increases as the standoff distance is over $8 \mathrm{~mm}$. The etching rate is dependent of reactive species concentration, velocity of flow and irradiation intensity. When the substrate is far from the nozzle, both reactive species concentration and irradiation intensity will be weak.
Fig. 11 Radial profiles of (a) temperature, (b) density, (c) axial velocity, and (d) radial velocity along the "POI"

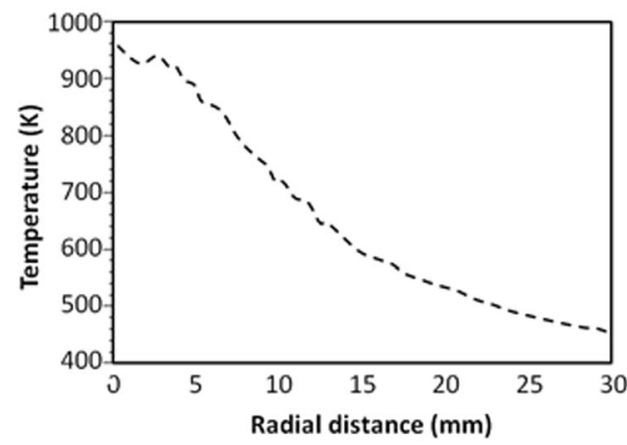

(a)

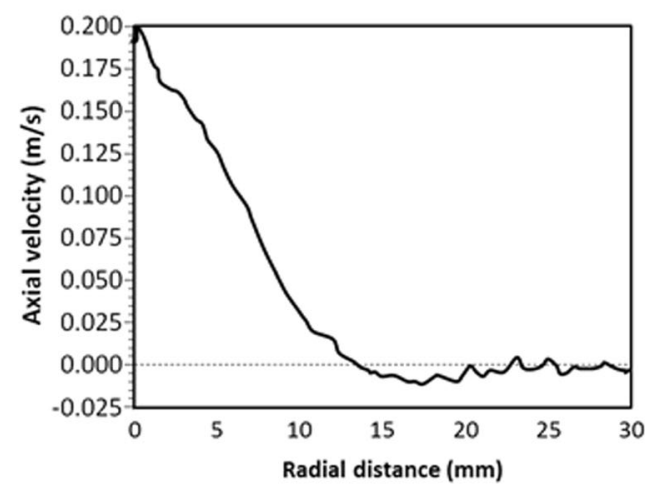

(c)

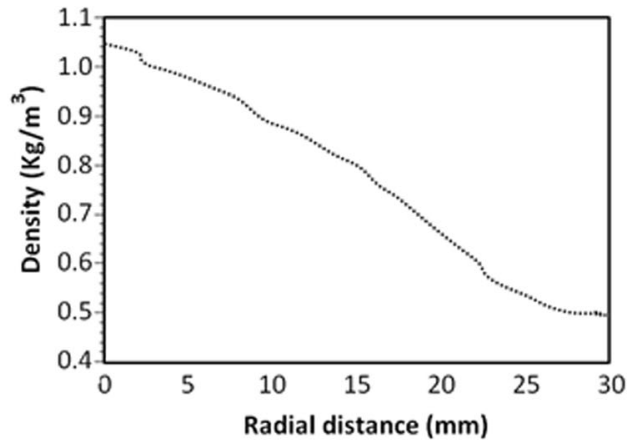

(b)

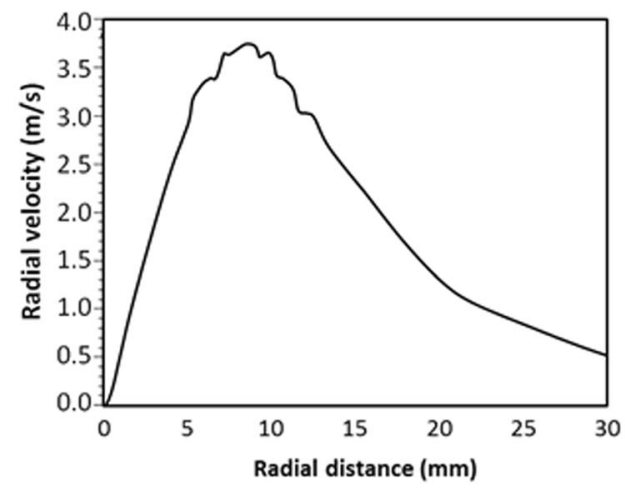

(d) 


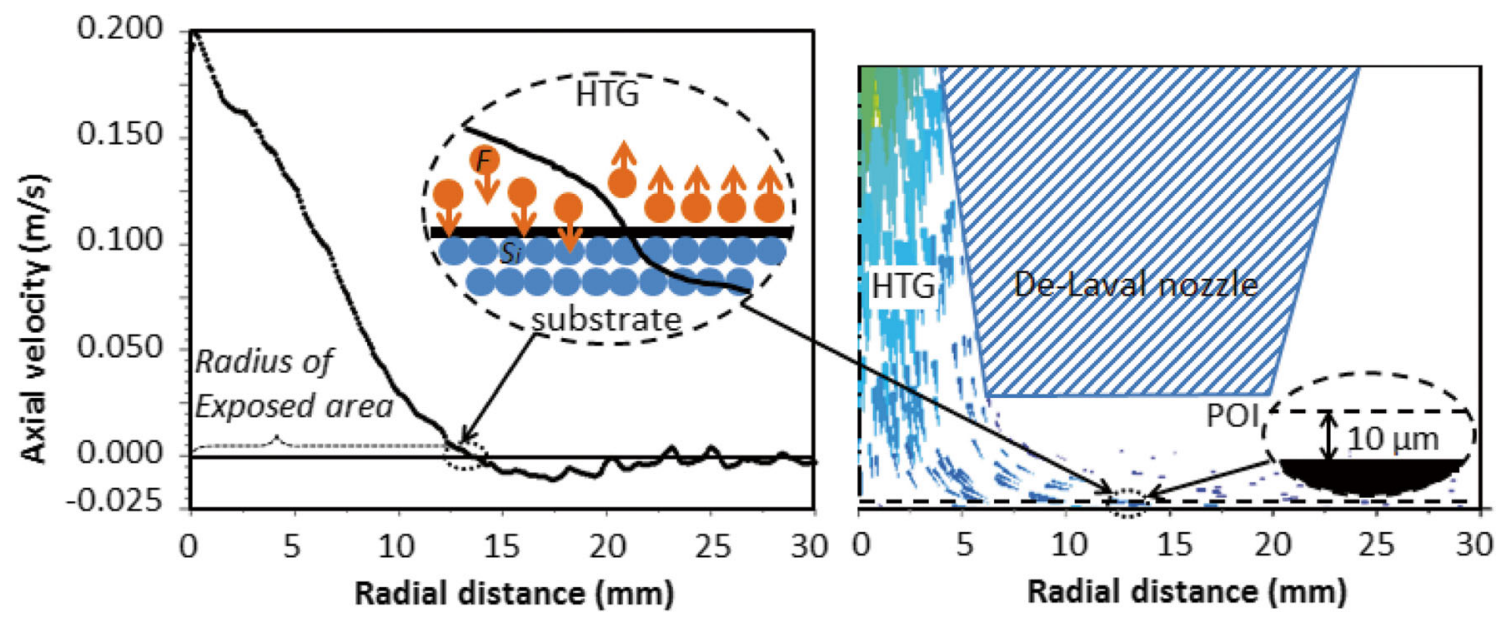

Fig. 12 Radial profile of the axial velocity along POI (left) and sketch of the HTG that flows onto the "Exposed area" (right)

\section{Discussion}

The understanding of the fluid dynamic behaviour of plasma flow settled between the inner part of the De-Laval nozzle and nearby surface requires a deep knowledge of the physics and a fine analysis of the processing conditions. Then some aspects of the model and experimental results are discussed hereafter. Three aspects are detailed: validation approach, model results, and nozzle design rules.

The validation approach of the author's model was carried out by comparing axial pressure and temperature profiles with the benchmark model found in [17]. As presented in Section 2.3, a discrepancy error of $5 \%$ was obtained. This error was attributed to the dependency of the pressure and the chemical composition of the plasma. However, the main point of this work is the creation of a model that supported and increased the understanding of the plasma jet in real and specific processing conditions. Like other researchers (Wang et al. [27]), the authors experienced strong changes of plasma

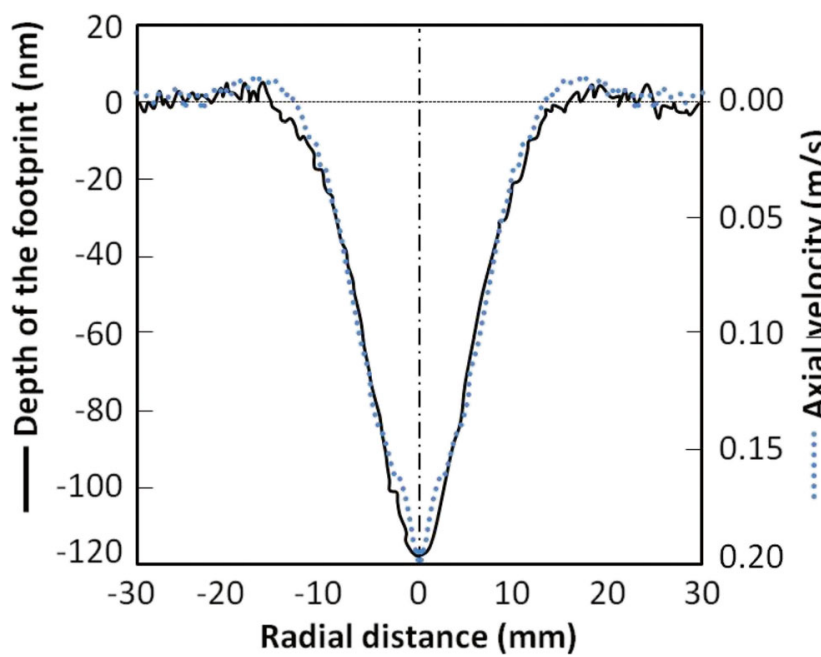

Fig. 13 Curves of the footprint (black solid line) and axial velocity of HTG along the POI (blue dotted line) temperatures, velocity, and density when a substrate is added to the experimental configuration. Unlike others, experimental setups [28-31] — used in plasma spraying process - where an 80-mm standoff distance enabled measurements, the present configuration-6-mm standoff-limited an experimental validation. This confined space would affect an OES investigation, where unwanted reflections of the light by the substrate and nozzle will degrade the collected spectrum quality. The harsh environment and the short standoff distance made measurements extremely challenging. Thus, authors considered that an alternative method was provided to correlate results of the CFD model with quantitative outputs.

Based on the validation stage outcome, the CFD model provided a sound ground for the scientific understanding of the flow dynamics in the nozzle when the flow was impinging a flat surface at short distance. The two assumptions madeHTG instead of plasma and parabolic profiles of temperature and velocity — enabled to reduce the complexity of model.

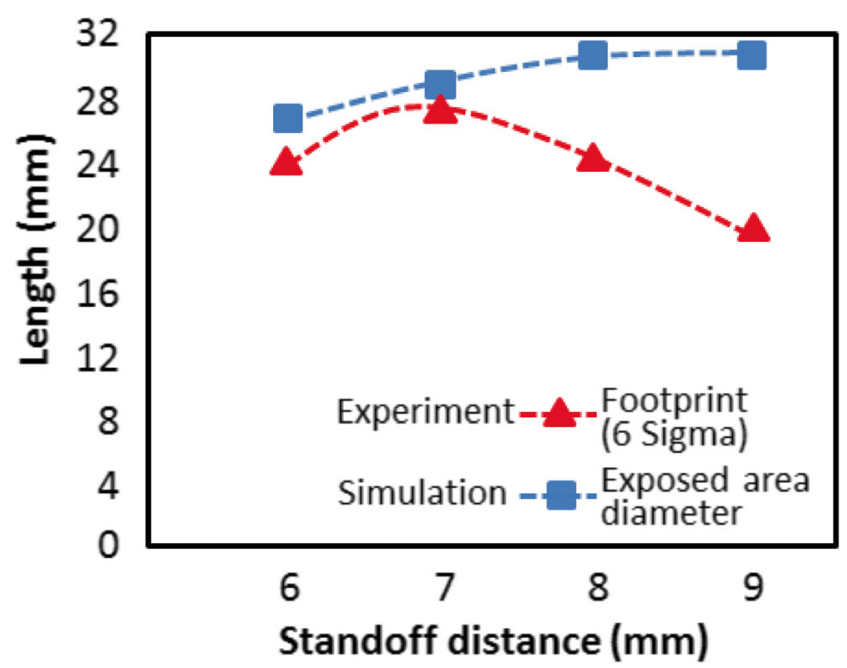

Fig. 14 Correlation between footprint 6 sigma values and exposed area diameters 
Consequently, the computational time was reduced without degrading the quality of the results.

The design of nozzles that are used for conveying subsonic plasma flow can be assisted by the present approach. In fact, the effects of different parameters of the nozzle (Fig. 5) can be investigated and adjusted for obtaining a specific velocity footprint of the gas flow. This work was already undertaken and partially detailed in [32] by the same authors. However, the present work benefited of an enhanced model that is more capable of estimating the optimum design parameters for a given material processing flow velocity and material removal footprint. Also, this further work will enable to investigate if the length of the divergent region improves or degrades the performance of jet as mentioned in [33]. To support this claim, the authors have planned a series of experiments where various nozzles mentioned in [32] will be tested.

\section{Conclusions}

A CFD model based on the HTG was developed for a DeLaval nozzle. This model was tested against the plasma torch model developed by Morsli and Proulx [17] with an acceptable degree of agreement. Compared to plasma models, the author's model proved that the use of HTG is sufficient for the actual De-Laval nozzle design characterization. In fact, the numerical results of this model highlighted that there are appropriate profiles of temperature and velocity applied on the nozzle inlet will reduce computational time. Furthermore the model enabled the investigation of the entire aerodynamic behaviour of HTG from the nozzle inlet up to the processed surface.

Acknowledgement This research work was funded by the Centre for Innovative Manufacturing in Ultra Precision (EP/I033491/1) of the Engineering and Physical Sciences Research Council (EPSRC) UK.

Open Access This article is distributed under the terms of the Creative Commons Attribution 4.0 International License (http:// creativecommons.org/licenses/by/4.0/), which permits unrestricted use, distribution, and reproduction in any medium, provided you give appropriate credit to the original author(s) and the source, provide a link to the Creative Commons license, and indicate if changes were made.

\section{References}

1. Boulos MI (1997) The inductively coupled radio frequency plasma. High Temp Mater Process: Int Quart High-Technol Plasma Process 1(1):17-39

2. Watanabe T, Okumiya H (2004) Formation mechanism of silicide nanoparticles by induction thermal plasmas. Sci Technol Adv Mater 5(5):639-646

3. Shigeta M, Sato T, Nishiyama H (2003) Numerical simulation of a potassium-seeded turbulent RF inductively coupled plasma with particles. Thin Solid Films 435(1):5-12
4. Gitzhofer F (1996) Induction plasma synthesis of ultrafine SiC. Pure Appl Chem 68(5):1113-1120

5. Reed TB (1961) Induction-coupled plasma torch. J Appl Phys 32(5):821-824

6. Carr JW (1999) Atmospheric pressure plasma processing for damage-free optics and surfaces. Eng Res DevTechnol 3:31-39

7. Chang A, Carr JW, Kelley J, Fiske PS (2007) U.S. Patent No. 7,304,263. Washington, DC: U.S. Patent and Trademark Office

8. Fridman A, Gutsol A, Cho YI (2007) Transport Phenomena in Plasma (Vol. 40). Academic Press

9. Castelli M, Jourdain R, Morantz P, Shore P (2012) Rapid optical surface figuring using reactive atom plasma. Precis Eng 36(3):467-476

10. Jourdain R, Castelli M, Shore P, Sommer P, Proscia D (2013) Reactive atom plasma (RAP) figuring machine for meter class optical surfaces. Prod Eng 7(6):665-673

11. Mostaghimi J, Proulx P, Boulos MI (1984) Parametric study of the flow and temperature fields in an inductively coupled rf plasma torch. Plasma Chem Plasma Process 4(3):199-217

12. Boulos MI (1985) The inductively coupled RF (radio frequency) plasma. Pure Appl Chem 57(9):1321-135

13. Nishiyama H, Muro Y, Kamiyama S (1996) The control of gas temperature and velocity fields of a RF induction thermal plasma by injecting secondary gas. J Phys D: Appl Phys 29(10): 2634-2643

14. Bernardi D, Colombo V, Ghedini E, Mentrelli A (2003) Threedimensional modelling of inductively coupled plasma torches. Eur Phys J D At, Mol, Opt Plasma Phys 22(1):119-125

15. Bernardi D, Colombo V, Ghedini E, Mentrelli A (2005) Threedimensional modeling of inductively coupled plasma torches. Pure Appl Chem 77(2):359-372

16. Colombo V, Ghedini E, Sanibondi P (2010) A threedimensional investigation of the effects of excitation frequency and sheath gas mixing in an atmospheric-pressure inductively coupled plasma system. J Phys D: Appl Phys 43(10):105202 (13pp)

17. Morsli M, Proulx P (2007) A chemical non-equilibrium model of an air supersonic ICP. J Phys D: Appl Phys 40(2):380-394

18. Morsli M, Proulx P, Gravelle D (2011) Chemical non-equilibrium modelling of an argon-oxygen supersonic ICP. Plasma Sources Sci Technol 20(1):015016 (11pp)

19. Fluent Inc. (2013) FLUENT Release 15.0, ANSYS Fluent User's Guide. ANSYS Inc

20. Belostotskiy SG, Khandelwal R, Wang Q, Donnelly VM, Economou DJ, Sadeghi N (2008) Measurement of electron temperature and density in an argon microdischarge by laser Thomson scattering. Appl Phys Lett 92(22):221507 (3pp)

21. Chen WLT, Heberlein J, Pfender E (1996) Critical analysis of viscosity data of thermal argon plasmas at atmospheric pressure. Plasma Chem Plasma Process 16(4):635-650

22. Rott N (1990) Note on the history of the Reynolds number. Annu Rev Fluid Mech 22(1):1-12

23. Morsli M, Proulx P (2007) Two-temperature chemically nonequilibrium modelling of an air supersonic ICP. J Phys D: Appl Phys 40(16):4810-4828

24. O'Brien W (2011) Characterisation and Material Removal Properties of the RAP ${ }^{\mathrm{TM}}$ Process (PhD thesis). Cranfield University, Cranfield, UK

25. Launder BE, Spalding DB (1974) The numerical computation of turbulent flows. Comp Methods Appl Mech Eng 3(2):269-289

26. Castelli M (2013) Advances in Optical Surface Figuring by Reactive Atom Plasma (RAP) (PhD thesis). Cranfield University, Cranfield, UK 
27. Wang HX, Chen X, Pan W (2007) Modeling study on the entrainment of ambient air into subsonic laminar and turbulent argon plasma jets. Plasma Chem Plasma Process 27(2):141-162

28. Bolot R, Imbert M, Coddet C (2001) On the use of a low-Reynolds extension to the Chen-Kim $(\mathrm{k}-\varepsilon)$ model to predict thermal exchanges in the case of an impinging plasma jet. Int $J$ Heat Mass Transfer 44(6): 1095-1106

29. Kang CW, Ng HW, Yu SCM (2006) Comparative study of plasma spray flow fields and particle behavior near to flat inclined substrates. Plasma Chem Plasma Process 26(2): $149-175$
30. Li HP, Pfender E (2007) Three dimensional modeling of the plasma spray process. J Therm Spray Technol 16(2):245-260

31. Selvan B, Ramachandran K, Pillai BC, Subhakar D (2011) Numerical modelling of Ar- $\mathrm{N}_{2}$ plasma jet impinging on a flat substrate. J Therm Spray Technol 20(3):534-548

32. Yu N, Jourdain R, Gourma M, Shore P (2014) Analysis of nozzle design used for the creation of advanced energy beam. ASPE, Annual meeting of American Society for Precision Engineering, Boston

33. Broc A, De Benedictis S, Dilecce G, Vigliotti M, Sharafutdinov RG, Skovorodko PA (2004) Experimental and numerical investigation of an $\mathrm{O}_{2} / \mathrm{NO}$ supersonic free jet expansion. J Fluid Mech 500:211-237 